\title{
The Effect of Pre-Weld Rolling on Distortion and Residual Stress in Fusion Welded Steel Plate
}

\author{
Harry E. Coules ${ }^{1, a}$, Luis D. Cozzolino ${ }^{1, b}$, Paul Colegrove ${ }^{1, c}$, Shuwen Wen ${ }^{2, d}$ \\ ${ }^{1}$ Welding Engineering Research Centre, Cranfield University, Cranfield, Bedfordshire, MK43 OAL, \\ United Kingdom \\ ${ }^{2}$ Tata Steel R, D \& T, Swinden Technology Centre, Rotherham, South Yorkshire S60 3AR, United \\ Kingdom \\ ah.e.coules@cranfield.ac.uk, 'I.cozzolino@cranfield.ac.uk, ${ }^{\mathrm{c} p}$.colegrove@cranfield.ac.uk, \\ 'shuwen.wen@tatasteel.com
}

Keywords: Weld rolling, Mechanical stress relief, GMAW, Thin plate, Welding distortion

\begin{abstract}
Local rolling and other mechanical tensioning techniques can be highly effective at reducing residual stress and distortion in thin plate welds prone to buckling. However, the issues of high capital cost and low scalability currently prevent wider adoption of such processes. Pre-weld rolling aims to address these issues and can be applied easily to each component prior to fabrication. The results of an initial trial are presented, and indicate that post-weld distortion can be reduced by an average of $38 \%$ when correct rolling parameters are used. Finally, the mechanism by which prerolling acts to modify the state of residual stress around a weld line is discussed.
\end{abstract}

\section{Introduction}

Residual stress and distortion in welded joints are caused by non-uniform heating and cooling during welding. Distortion problems are especially prominent whenever thin materials prone to buckling are welded, and are common in the shipbuilding and aerospace industries. Many in-process stress reduction techniques have been investigated yielding encouraging results, including both thermal [1-3] and mechanical [4,5] methods. However, long-established thermal methods such as annealing and flame straightening are predominantly used industrially, despite being rather labourintensive [6].

Localised rolling along or close to a weld seam as a method of residual stress reduction has been investigated sporadically since at least the 1960s [7-11], with generally very encouraging results. However it is still a rather immature technology with several outstanding issues hampering widespread use. For example, local rolling involves the application of a large compressive force to a small area of the workpiece, which is necessary to achieve the substantial plastic strain required. Consequently the equipment required for this type of rolling is typically very large. The essential components which comprise this are a large stiff structure to support the roller over the workpiece and a system, usually hydraulic, to apply the load (see Figure 1). This makes rolling unsuitable for use in many applications, since it means that as-welded assemblies must be brought to the rolling rig, which itself cannot be made portable.

If a state of residual stress could be induced in components prior to welding, such that it wholly or partially cancelled the stress produced by the weld, there would be no need to roll the assembly subsequently. Plates could be pre-rolled along the edges due to be joined, and then assembled. This pre-rolling technique would be easy to accomplish compared with rolling either during or after welding.

Mechanisms of stress formation and reduction. During welding, compressive plastic strain in an area surrounding the weld line is induced by a cycle of expansion, softening and constrained contraction of the parent material under a non-uniform thermal field, resulting in a large tensile residual stress in the longitudinal direction of the weld. In-process stress reduction techniques work 
by reducing the amount of compressive yielding ahead of the heat source and/or inducing tensile plastic strain behind it, both of which counteract the thermal strain effect. For example, the use of an intense cooling device trailing the heat source increases the amount of tensile plastic strain behind it, as shown by van der Aa et al. [12]. By contrast, Global Mechanical Tensioning (GMT) involves the application of a large longitudinal stretching force to the workpiece as it is welded. Again, this increases tensile yielding behind the heat source, but also decreases compressive yielding in front of it [4].

The fundamental mechanism by which rolling acts is by compressive deformation of material in the direction normal to the rolled surface, which by the Poisson effect causes expansion in the inplane directions. This has been used recently by Williams and coworkers $[10,11,13]$, and previously by a number of others $[8,9,14,15]$, for both in-process and post-weld deformation of material close to the weld line. With the exception of that by Liu et al. [15], all of these experiments have used this in-plane tensile yielding to either prevent or relieve longitudinal residual stresses.

For this study, two possible mechanisms by which pre-weld rolling could reduce post-weld residual distortion in thin plate welds were proposed. Firstly, rolling produces a compressive residual stress underneath the roller path. If rolling were carried out over a thin region parallel to and slightly removed from the weld line, then this compressive stress might be equilibrated by a tensile one lying partly along the weld line. This tensile stress would then have a stretching effect during welding similar to that of GMT, and the consequent reduction in residual stress would prevent or reduce the appearance of buckling deformation. Second, the roller might introduce stresses which were asymmetric about the mid-plane of the plate, causing a small amount of bending. If aligned so as to counteract the welding-induced buckling distortion this might give an overall reduction in final distortion, though not a significant reduction in residual stress.

\section{Experimental}

Rolling equipment. An experimental rolling machine was designed for a maximum rolling force of $200 \mathrm{kN}$; the load is applied directly to the roller axis by a hydraulic cylinder mounted vertically and attached to the machine's crossbeam. The workpiece is attached to the machine bed using a vacuum clamping system. To roll the sample, a constant force is applied and the whole crossbeam assembly is moved in the rolling direction by a pair of motor-driven leadscrews (see Figure 1). The compressive force is monitored using a load washer between the hydraulic cylinder and the roller head. The device also has an attachment for a welding torch, allowing rolling and welding to be carried out with the same machine.

Method. To test the pre-rolling method, butt welds were made between pairs of $4 \mathrm{~mm}$-thick plates of S355 structural mild steel, with each individual plate measuring $500 \mathrm{x} 200 \mathrm{~mm}$. The samples were pre-rolled prior to welding using the rolling machine designed for these experiments. Three basic rolling parameters were varied to assess their effect on the welded sample: the
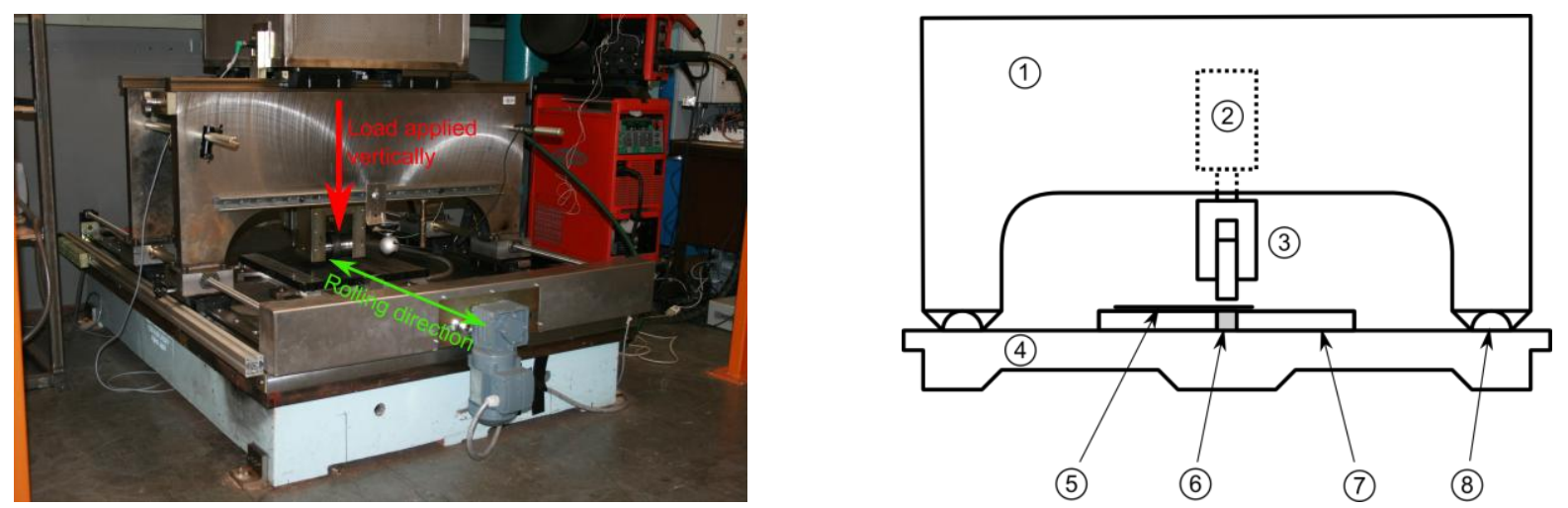

Figure 1: Experimental machine for single-sided rolling. 1. Crossbeam 2. Hydraulic cylinder 3. Roller fork 4. Bed 5. Workpiece 6. Backing bar 7. Vacuum clamps 8. Drive screw 
Table 1: Welding parameters used in joining the rolled plate samples.

\begin{tabular}{|c|c|}
\hline Process & GMAW (pulsed) \\
\hline Power supply & $\begin{array}{l}\text { Fronius TransPuls } \\
\text { Synergic } 5000\end{array}$ \\
\hline $\begin{array}{r}\text { Contact tip to work } \\
\text { distance (CTWD) }\end{array}$ & $16 \mathrm{~mm}$ \\
\hline Torch angle & $90^{\circ}$ \\
\hline Filler wire diameter & $1 \mathrm{~mm}$ \\
\hline Filler wire feed speed & $242 \mathrm{~mm} \mathrm{~s}^{-1}$ \\
\hline Travel speed & $10.8 \mathrm{~mm} \mathrm{~s}^{-1}$ \\
\hline Current & $330 \mathrm{~A}$ \\
\hline Voltage & $31.7 \mathrm{~V}$ \\
\hline Gas composition & $\begin{array}{l}5 \% \mathrm{CO}_{2}, 2 \% \mathrm{O}_{2}, \\
\text { balance } \mathrm{Ar}\end{array}$ \\
\hline Gas flow rate & $233 \mathrm{ml} \mathrm{s}^{-1}$ \\
\hline
\end{tabular}

Table 2: Rolling parameters used in Set A; for each combination of load and distance one sample was rolled on the upper side and one on the lower. *Set B contained an additional ten samples with this combination: five rolled on the upper side and five on the lower.

\begin{tabular}{ccccc}
\hline Distance & \multicolumn{4}{c}{ Load (kN) } \\
\cline { 2 - 5 } from weld line \\
$\boldsymbol{y}_{\text {roll }}(\mathbf{m m})$ & 25 & 50 & 100 & 200 \\
\hline 15 & $\mathrm{x}$ & $\mathrm{X}$ & $\mathrm{X}$ & \\
25 & $\mathrm{x}$ & $\mathrm{X}$ & $\mathrm{x}$ & \\
35 & $\mathrm{x}$ & $\mathrm{x}$ & $\mathrm{x}$ & \\
55 & & & $\mathrm{x}$ & $\mathrm{x}$ \\
75 & & & $\mathrm{x}$ & $\mathrm{x}^{*}$ \\
\hline
\end{tabular}

compressive force transmitted through the roller, the distance $\left(\mathrm{y}_{\text {roll }}\right)$ between the edge of the plate and the centre of the roller's contact path, and whether the roller was applied to the upper or lower surface of the plate. The upper surface of the plate was defined as the side from which the plate was welded.

Two groups of samples were manufactured using pre-weld rolling in addition to ten control samples which were welded without any rolling treatment. For the first, Set A, two pairs of plates were welded for each of the combinations of rolling parameters in Table 2, one pair each for rolling on the upper and lower sides. For Set B, rolling was carried out at a single combination of load and distance: $200 \mathrm{kN}$ at $55 \mathrm{~mm}$ from the weld line. Five pairs of plates were rolled on the upper side and five on the lower side with these parameters.

During rolling, each individual plate was held securely with a vacuum clamp as the roller passed over it parallel to the edge to be welded. In all cases, only a single pass of rolling was used. To avoid damage to the clamps, the area of the plate directly underneath the path of the roller was backed with a steel backing bar, which could be replaced with a copper one for use during welding. The roller itself was $30 \mathrm{~mm}$ wide, $100 \mathrm{~mm}$ in diameter and made from hardened EN24 steel; the speed at which it traversed the plate during rolling was $8.33 \mathrm{~mm} \mathrm{~s}^{-1}(50 \mathrm{~cm} / \mathrm{min})$.

Welding parameters. After rolling, the edges to be welded were cleaned with acetone. Each pair of plates was tack-welded in four places to hold them together, and the samples were then joined along their length using single-pass pulsed GMAW. The parameters used for this process, summarised in Table 1, were designed to give full penetration of the fusion zone (where the metal had been fully melted) through the whole thickness of the plate, without using a root gap separating the plate edges. The welding parameters used were identical for every sample.

Distortion measurement. To quantify the distortion present in each sample, it was placed on a flat measuring table and scans of the upper surface were taken using a laser measurement device (Romer Omega-arm and an R-Scan laser scanning head). This produced a series of measurement points which was used to fit a rectangular grid of $20 \times 20 \mathrm{~mm}$ elements over the whole of the plate's surface; since each sample had nominal dimensions of $500 \times 400 \mathrm{~mm}$ this resulted in a grid of $25 \mathrm{x}$ $20=400$ elements and $21 \times 26=546$ nodes. The out-of-plane displacements of these nodes were averaged to produce a single value representing the mean distortion for each plate. 


\section{Results and discussion}

Results for Set A are shown in Figure 2, separated into plots for samples rolled on the upper and lower sides. The average out-of-plane displacement of the ten un-rolled control samples was 6.15 $\mathrm{mm}$; this was used as a baseline against which distortion measurements from the rolled samples could be compared, and is included as a horizontal chain line. For samples rolled on the upper side (Figure 2a) there is a slight upward trend between distortion and roller load, indicating that rolling on this side is having a detrimental effect. However, the opposite trend is seen for samples which were rolled at higher distances from the weld line $(35,55$ and $75 \mathrm{~mm})$ on the lower side. In all cases, for lower roller loads $(25$ and $50 \mathrm{kN})$, the distortion does not deviate significantly from the mean distortion of the un-rolled samples. Hence, for this material a very large load is required to generate an observable difference in distortion post-weld.

Sample Set B was used to further investigate a particular combination of rolling parameters with comparison to the un-rolled state, and clarify the differences in the effect of upper and lower side rolling. The parameters were chosen based on the lowest-distortion result observed in Sample Set A: rolling at $55 \mathrm{~mm}$ from the plate edge, at a load of $200 \mathrm{kN}$, and on the lower side of the plate. Figure 3 compares the mean values of average displacement for samples rolled with these parameters. The difference in residual distortion between the different cases is clear: the displacement of samples rolled on the lower side is on average 38\% lower than that of un-rolled ones, while that of samples rolled on the upper side is $20 \%$ higher. Also noticeable in this figure is the moderate amount of variation in residual distortion for samples processed with identical parameters, which indicates the need for replication if measured distortion results are to be compared with computational models or used to draw strong conclusions.

Figure 4 has been used to illustrate further the differences in distortion observed in Set B; the composite surfaces have been constructed by taking the average over the sample set of the vertical

a.

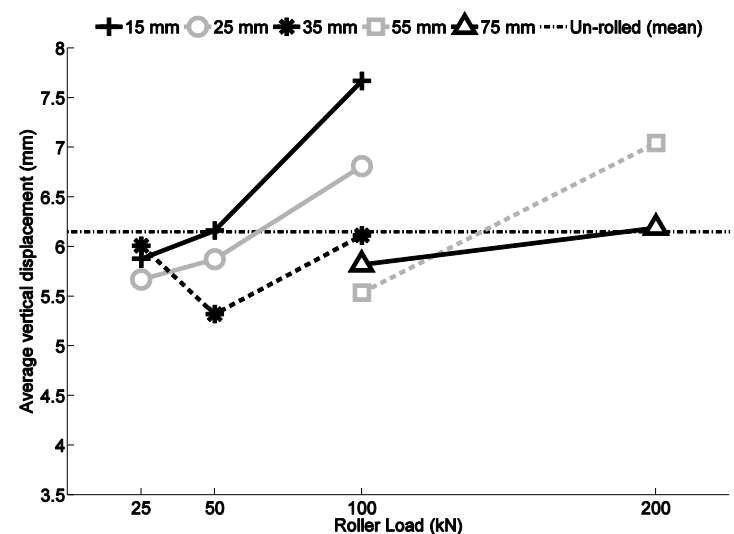

b.

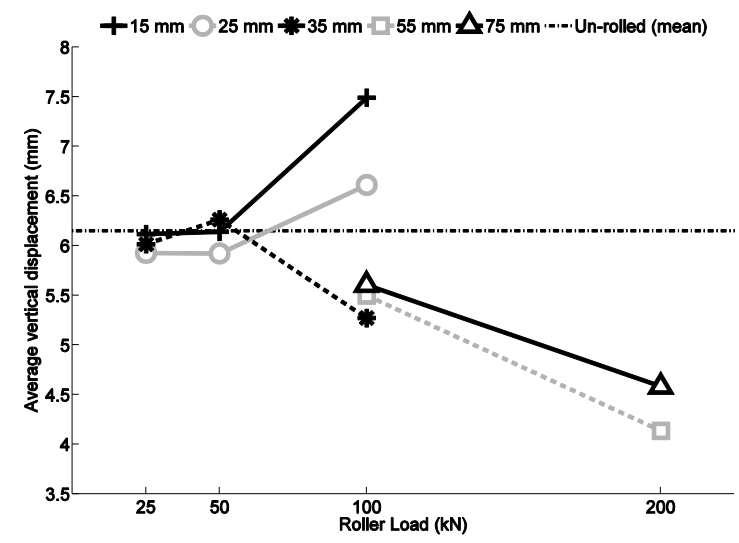

Figure 2: Average vertical displacement of rolled plates in experimental Set A. (a) Plates rolled on upper (welded) side (b) plates rolled on lower side.

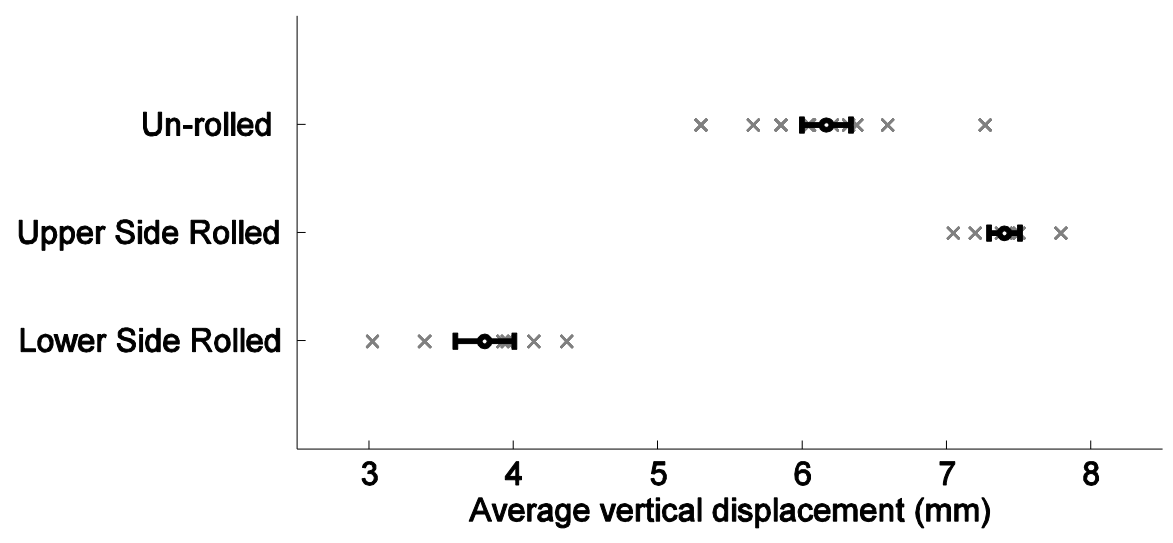

Figure 3: Comparison of average vertical displacements for un-rolled samples, samples rolled at $200 \mathrm{kN}$ and $55 \mathrm{~mm}$ from weld line on the upper side, and samples rolled at 200 $\mathrm{kN}$ and $55 \mathrm{~mm}$ from the weld line on the lower side. (Error bars represent the $95 \%$ confidence interval of the mean.) 
displacement at each measurement point on the sample's surface. The surface representing samples rolled on the lower side is visibly flatter than both the surface for un-rolled samples and the surface for samples rolled on the upper side.

If the amount of plastic strain during rolling was approximately uniform over the plate thickness, then the state of stress induced by rolling, and therefore the post-weld distortion, would be similar for rolling on the upper and lower sides of the plate. However, comparison of the samples rolled on opposite sides in Figures $4 \mathrm{~b}$ and $4 \mathrm{c}$ shows that this is not the case. A similar difference in distortion was observed by Wescott [13] in post-weld rolling of a very similar material with identical thickness. It can therefore be concluded that there is significant through-thickness variation in yielding with this roller and backing bar design, during both pre- and post-weld rolling. This implies that it is the bending deformation caused by this variation, rather than an overall reduction in weldinduced residual stresses, that is the primary mechanism by which post-weld distortion is modified by pre-weld rolling.

\section{Conclusions}

The use of pre-weld local rolling to reduce welding-induced buckling of mild steel plate has been investigated and found to be viable: it has been demonstrated that distortion can be decreased by an average of $38 \%$ using this method. With optimisation of the rolling parameters, it may well be possible to achieve an even more pronounced reduction. A significant force $(200 \mathrm{kN})$ normal to the surface of the workpiece was required to achieve the largest improvements observed during this study; for the roller geometry used here on $4 \mathrm{~mm}$-thick steel samples, pre-weld rolling loads in the range $0-100 \mathrm{kN}$ were found have relatively little influence on the final distortion.

The pre-weld rolling process described here induces a state of residual stress in the material which varies significantly over its thickness; this was indicated by a marked difference in post-weld distortion between plates which had been rolled on opposite sides. To achieve a reduction in distortion it is necessary to roll on the side opposite to that from which the plate is subsequently welded. It is therefore proposed that for this type of pre-weld rolling, bending deformation is the primary mechanism by which the distortion is reduced, rather than any overall decrease in residual stress close to the weld line. Future studies will focus on modelling to better understand these deformation mechanisms, on increasing the scalability of the technique, and on a variety of closely related rolling processes.

A small amount of variation in the magnitude of buckling distortion for similar samples can be seen in the experimental results. Although expected due to the unstable nature of this distortion

a.
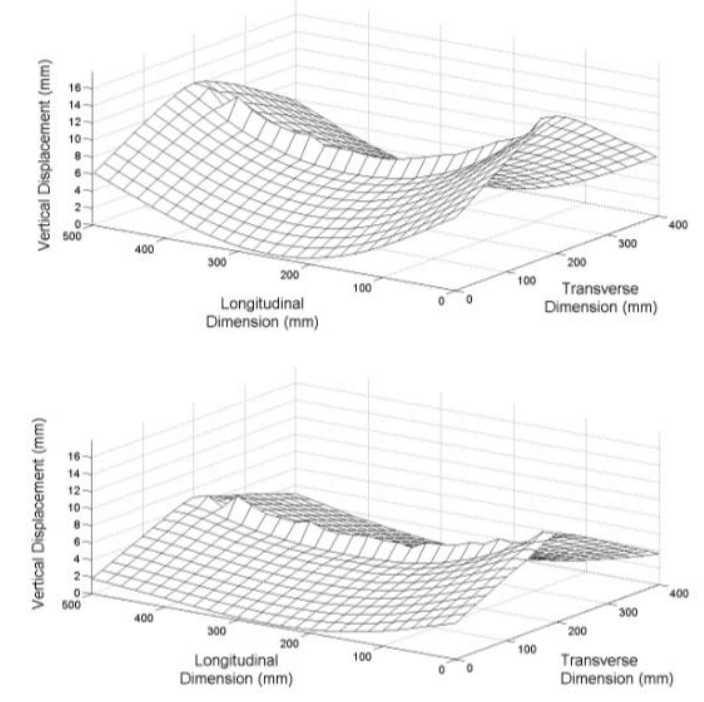

c. b.

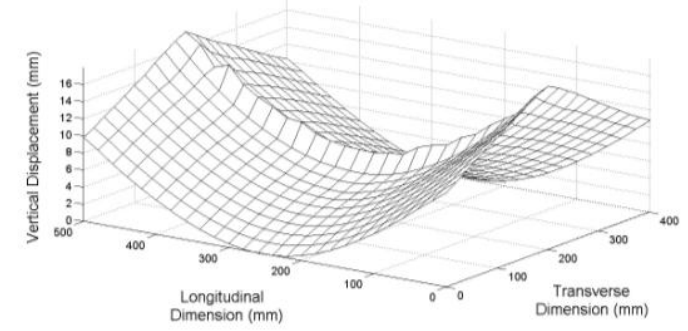

Figure 4: Composite images representing the average buckling displacements of (a) plates welded without rolling (b) plates rolled on the upper side (c) plates rolled on the lower side. In all cases, rolling is at $200 \mathrm{kN}$ and $55 \mathrm{~mm}$ from the weld line. Displacements on the vertical axis have been magnified 10x for clarity, and the welding direction is from left to right. 
mode, it highlights the necessity of sample replication in studies involving buckling under residual stress.

\section{Acknowledgements}

The authors wish to acknowledge funding for this project from Tata Steel Europe and from the EPSRC under grant no. EP/G014132/1.

\section{References}

[1] Q. Guan, D. L. Guo, C. Q. Li and R. H. Leggatt: Weld. World Vol. 33 (1994), p. 160

[2] P. Michaleris and X. Sun: Weld. J. Vol. 76 (1997), p. 451-s

[3] M. V. Deo and P. Michaleris: Sci. Technol. Weld. Joi. Vol. 8 (2003), p. 49

[4] D. G. Richards, P. B. Prangnell, S. W. Williams and P. J. Withers: Mat. Sci. Eng. A Vol. 489 (2008), p. 351

[5] D. A. Price, S. W. Williams, A. Wescott, C. J. C. Harrison, A. Rezai, A. Steuwer, M. Peel, P. Staron and M. Kocak: Sci. Technol. Weld. Joi. Vol. 14 (2007), p. 620

[6] N. A. McPherson: Weld. J. Vol. 89 (2010), p. 30

[7] S. A. Kurkin and G. Tsyao: Weld. Prod. Vol. 10 (1962), p. 1

[8] S. A. Kurkin and V. I. Anufriev: Weld. Prod. Vol. 31 (1984), p. 52

[9] G. F. Kondakov: Weld. Int. Vol. 2 (1988), p. 172

[10] J. Altenkirch, A. Steuwer, P. Withers, S. Williams, M. Poad and S. Wen: Sci. Technol. Weld. Joi. Vol. 14 (2009), p. 185

[11] S. W. Wen, S. W. Williams, S. A. Morgan, A. Wescott, M. Poad and G. Moore in: Proceedings of the 9th International Seminar Numerical Analysis of Weldability (2009)

[12] E. M. van der Aa, M. J. M. Hermans and I. M. Richardson: Sci. Technol. Weld. Joi. Vol. 11 (2006), p. 488

[13] A. Wescott: Master's Thesis (Cranfield University 2009)

[14] S. A. Kurkin, V. I. Anufriev and E. S. Milekhin: Weld. Prod. Vol. 27 (1980), p. 20

[15] W. Liu, X. Tian and X. Zhang: Weld. J. Vol. 75 (1996), p. 297-s 